\title{
EL DERECHO PENAL ANTE EL MALTRATO DE ANIMALES
}

Vicenta Cervelló Donderis*

\section{Resumen}

La tutela penal frente al maltrato de animales provoca diversos problemas de interpretación, siendo el más importante de ellos la justificación de su regulación desde el prisma de ultima ratio del derecho penal y, con ello, la necesidad de justificar un bien jurídico digno de protección. A partir de ese presupuesto, el reto pasa a ser la concreción del objeto de tutela dentro de la diversidad de especies animales y la delimitación entre las conductas punibles y las conductas autorizadas.

\section{Palabras clave}

Maltrato animal, antropocentrismo, biocentrismo, derecho penal, Ley Orgánica 1 de 2015, Ley 1774 de 2016.

\begin{abstract}
Criminalizing animal cruelty causes multiple interpretation problems. The most significant are to justify these criminal sanctions according to the ultima ratio principle and to identify the legally protected right or interest. Besides, it is also problematic to establish which animals are protected and which conducts are subject to imprisionment.
\end{abstract}

\section{Keywords}

Animal cruelty, anthropocentrism, biocentrism, criminal law, Organic law 1 of 2015, Act 1774 of 2016, Bull fights, dog fights.

\section{Introducción}

La reciente aprobación en Colombia del delito de maltrato animal (Ley 1774 de 2016) y la ampliación en la última reforma del Código Penal español del ya existente delito de maltrato animal (Ley Orgánica 1 de 2015) han vuelto a poner de relieve el interés por esta problemática, justificando una breve reflexión sobre la cada vez más extensa tendencia a considerar a los animales como sujetos de derechos susceptibles de tutela jurídica y, en particular, de protección penal.

La tutela de los derechos de los animales viene experimentando una gran evolución en los últimos años, ya que desde su inicial cobijo en las normas administrativas ha llegado al derecho penal,

\footnotetext{
*Universitat de València (España).
} 
donde se han planteado numerosas e interesantes cuestiones. Entre ellas se puede destacar la compatibilidad de esta nueva figura delictiva con el carácter de ultima ratio del ordenamiento punitivo, las dificultades para identificar un bien jurídico protegido autónomo y no dependiente de otros, las diferencias entre los distintos tipos de animales como objeto de protección o los diversos usos y costumbres utilizados para justificar -por adecuación social- diferentes actos de maltrato, sacrificio y explotación de animales. Función del derecho en este sentido es argumentar la necesidad de intervención penal, delimitar el marco legal de protección, y resolver los conflictos sociales desde la ponderación de derechos e intereses de seres humanos y animales.

El debate sobre el maltrato animal, y la necesidad de su regulación, alcanza a una serie de conductas que, pese a ser muy distintas entre sí, tienen en común la producción de actos de verdadero sufrimiento y ha impulsado la reflexión sobre la ética del comportamiento humano con los animales. De esta forma, cuando se habla de maltrato animal no solo se hace referencia a los actos de maltrato propiamente dichos, por regla general sobre animales domésticos, sino también a las celebraciones tradicionales que, en diversos lugares del planeta, utilizan el sufrimiento animal como divertimiento y a las prácticas científicas o de sacrificio que pudiendo evitarles daños innecesarios, no lo hacen.

En España, la protección penal de los animales comenzó en 1995 con la introducción del maltrato de animales domésticos como infracción leve, regulada en el art. 632 del Código Penal. Posteriormente, la norma sufrió varias modificaciones, todas ellas para ampliar el objeto de protección y las conductas punibles, siendo especialmente relevante que en 2003 (Ley Orgánica 15) pasó a ser un delito, regulándose en el art. 337 del Código Penal. En 2010 (Ley Orgánica 5), se amplió el objeto de protección para incluir los animales amansados y se flexibilizó la conducta al suprimir la necesidad de ensañamiento en el maltrato. Por último, en 2015 (Ley Orgánica 1), se ha vuelto a ampliar el objeto de protección, alcanzando prácticamente a todo tipo de animal y se crearon nuevas conductas punibles.

En la actualidad, el delito español tiene cuatro modalidades diferentes: maltrato cruel de animales domésticos; maltrato injustificado de todos los animales, menos los salvajes, que les cause la muerte, lesiones graves o explotación sexual; agravaciones por los medios empleados o los resultados producidos; y maltrato a cualquier animal en espectáculos no autorizados. Todos los tipos recaen sobre una conducta previa de maltrato, bien sea injustificado o cruel, lo que, además de no contemplar el castigo de la muerte o lesiones sin dicho maltrato, da a entender que caben maltratos justificados o no crueles.

Estas reformas legislativas son el resultado del consenso alcanzado en torno a mejorar la protección jurídica de los animales, no en erradicar todos los daños que sufren, donde hay más diferencias a la hora de concretar 'el qué y el cómo'. Con ello, a la regulación administrativa se suma la tutela penal para los supuestos de mayor gravedad, siendo necesario esforzarse en fundamentar un adecuado bien 
jurídico para delimitar qué tipo de animales y qué conductas específicas justifican la intervención penal.

La Liga Internacional de los Derechos del Animal aprobó, en 1977, la Declaración Universal de los Derechos del Animal, que posteriormente fueron aprobados por la Asamblea General de Naciones Unidas y la UNESCO. Allí, después de reconocer en el Preámbulo que todos los animales poseen derechos, que los hombres cometen graves atentados contra ellos y contra la naturaleza, que el respeto a otras especies es el fundamento de la coexistencia, que el respeto de los hombres a los animales es vinculante al propio respeto entre los hombres y que a través de la educación se ha de proporcionar el respeto y afecto a los animales, recoge un catálogo de derechos entre los que destacan, por su relación con las conductas de maltrato, los siguientes:

Art. 2: Todo animal tiene derecho al respeto. Todos los animales tienen derecho a la atención, a los cuidados y a la protección del hombre.

Art. 3: Ningún animal será sometido a malos tratos ni a actos de crueldad. Si es necesaria la muerte de un animal, ésta debe ser instantánea, indolora y no generadora de angustia.

Art. 6: El abandono de un animal es un acto cruel y degradante.

Art. 7: Todo animal de trabajo tiene derecho a una limitación razonable del tiempo e intensidad del trabajo, a una alimentación reparadora y al reposo.

Art. 11: Todo acto que implique la muerte del animal sin necesidad es un biocidio, es decir, un crimen contra la vida.

Como se puede observar, es una lista de principios programáticos de 'buen gobierno' entre humanos y animales, pero insuficiente para abordar todos los actos de maltrato, agresiones y abandono que sufren estos últimos e incapaz de dar una respuesta clara a todo tipo de conductas. A pesar de ello, es cierto que, desde su expedición, han ido cambiando paulatinamente las políticas legislativas dedicadas a regular las prácticas y actividades con animales en orden a mejorar su bienestar ${ }^{1} \mathrm{y}$ han aumentado las críticas a conductas socialmente toleradas, pese a los sufrimientos físicos o psicológicos que conllevan, como las exhibiciones y los espectáculos que se sirven de animales para deleite de los seres humanos o el uso de animales en escenas de violencia de los medios audiovisuales, que son prácticas cada vez más rechazadas.

La necesidad de proteger los derechos de los animales y, en particular su vida, su salud, su integridad física y psíquica, plantea si es suficiente con la tutela que otorga el derecho administrativo, donde se dictan normas de protección, pero también

${ }^{1}$ Estos cambios han producido una nueva ética del consumidor dirigida a coordinar las políticas económicas y sociales con una mayor preocupación por el bienestar animal (Hava, 2011, p. 264). 
normas de autorización. En el primer sentido, se regula el sacrificio, explotación y experimentación con animales para minimizar su sufrimiento y se sancionan las conductas de maltrato sobre animales domésticos por su especial vulnerabilidad. En el segundo, como reglas de autorización, se regulan actividades con animales de forma más individualizada a través de normas locales o regionales que reflejan la diversidad social y cultural de los hábitos y las costumbres de los seres humanos que involucran animales.

Cuando la tutela administrativa se entiende insuficiente, cobra relevancia el debate sobre la entrada en escena del derecho penal, cuya intervención se justifica por la gravedad de las conductas. Con todo, dicho recurso no siempre es bien recibido por las dudas que suscita el hecho de elevar a los animales a la categoría de 'objeto' necesitado de protección penal y el rechazo frente a la expansión punitiva que propicia la incapacidad de otros ámbitos jurídicos para resolver los conflictos sociales.

Teniendo en cuenta las anteriores consideraciones, a continuación se va a realizar una breve reflexión sobre los elementos típicos más relevantes de los delitos de maltrato animal, centrando la atención en los aspectos relacionados con el bien jurídico protegido, las conductas con relevancia penal, el objeto de protección y las autorizaciones legales.

\section{Los animales como sujetos de derechos: ¿derechos de los animales?}

Para articular la protección penal frente al maltrato animal debe determinarse si los animales mantienen una relación de pertenencia y dependencia respecto a los humanos o si, por el contrario, se puede entender que son sujetos de derechos. En el primer sentido, se trata de mantener que la categoría de los derechos está ligada en exclusiva a las personas y a sus intereses y, por ello, los animales sólo pueden ser objeto de tutela en tanto propiedad de las personas, mientras que, en el segundo aspecto, se puede partir del respeto absoluto a los derechos de todos los animales o, bien, seleccionar un tipo específico de animales atendida su mayor proximidad a los humanos o una serie de derechos considerados esenciales debido a su importancia.

\section{Planteamiento antropocéntrico.}

La existencia de un entramado legislativo de normas destinadas a garantizar la convivencia pacífica a través de la regulación de derechos y deberes, siempre ha considerado al ser humano como su destinatario exclusivo - puede reclamar y exigir su cumplimiento- por ser el único que reúne las condiciones mínimas normativas. En este sentido, el ser humano recibe la protección de las normas penales cuando alguno de esos derechos resulta vulnerado por cualquier conducta delictiva.

Entre los derechos que reciben protección penal, algunos son consustanciales a la persona humana y por ello se les denomina personalísimos, como es el caso de la vida, la libertad, la dignidad humana, el honor o la intimidad; otros son derechos 
relativos a la persona humana en tanto miembro de un grupo social y los afectan los delitos de riesgo o los que atentan contra los intereses colectivos; y otros son derechos que surgen de la relación de las personas con las cosas, a propósito de lo cual hay una estrecha relación entre los derechos penal y civil patrimonial, pues el último regula la relación de las personas con los objetos.

Tradicionalmente, los animales han sido considerados cosas objeto de propiedad en el derecho civil, a salvo de algunas normas específicas y, como señala Muñoz (1999, pp. 47-48), esa aproximación no sólo no distingue entre los distintos tipos de animales, sino que, cuando se ha hecho a través de leyes especiales, siempre ha sido en interés del hombre y nunca con una finalidad de protección distinta, lo que implica su consideración exclusiva como provecho, fuente de riqueza o valor económico.

Entender a los animales como objeto de propiedad de los hombres desde una visión estrictamente antropocéntrica, en la que la preferencia de los intereses de los humanos dota a los animales de un mero valor instrumental, supone rechazar toda postura que reconozca derechos propios a los animales (no se puede reconocer el derecho a la vida o a la integridad física de los animales). De esta forma, las conductas de maltrato protegen en todo caso los sentimientos de las personas (Roca, 2000, p. 401); esto es poco convincente, porque supone ignorar el daño sufrido por el propio animal. Lo mismo sucede cuando se limita la tutela penal a los maltratos crueles de animales domésticos, justificado en las especiales obligaciones de carácter bioético que exigen tratarlos de manera adecuada (Higuera, 1998, p. 349), ya que, además de ser un concepto cada vez más difícil de concretar, olvida la necesidad de tutela de otros animales que también gozan de la capacidad de sentir.

Esta postura ha dominado en la doctrina penal que, en general, no se muestra partidaria de reconocer los derechos de los animales como bien jurídico y no admite su consideración como sujeto pasivo, entendiendo preferible la opción del castigo de estas conductas en el ámbito administrativo (Cobo del Rosal, 2005, p. 727). Es decir, su rechazo no es a la protección de los derechos de los animales, sino a la necesidad de que reciban tutela penal, teniendo en cuenta el carácter subsidiario de esta rama del derecho y las dificultades para configurar un bien jurídico autónomo.

Los problemas para reconocer los derechos de los animales sobre una controvertida estructura jurídica han permitido afirmar que se trata, más bien, de proteger sus intereses para limitar las conductas de los seres humanos y preservarles de agresiones y abusos; por ello, se alude a unos deberes de los seres humanos en sus relaciones con animales, cuyo cumplimiento se garantiza a través de la coacción (Muñoz, 1999, p. 111). De esta manera, se defiende que las leyes de protección de los animales ni crean derechos subjetivos ni elevan a los animales a la categoría de personas, sino que se ocupan de regular los deberes y obligaciones de los humanos en su relación con los animales. 
Lo positivo de esta postura es que ha servido para iniciar los cambios legislativos que permiten abandonar la tradicional consideración del animal como objeto personal a disposición de su propietario, sustituyéndola por un tratamiento o enfoque de prioritario interés social y público; lo negativo, sin embargo, es que desatiende todo el desarrollo teórico que se ha ido construyendo sobre los derechos de los animales desligados de su relación con los seres humanos y que posibilitan una lectura ética de la comunidad moral formada por humanos y ciertos animales considerados más próximos por tener capacidad de sentir.

\section{Postura animalista o biocéntrica.}

Quienes defienden los derechos de los animales lo hacen desde dos puntos de vista diferentes: de un lado, el que, a partir de la 'comunidad de iguales', entiende que no hay diferencia entre derechos humanos y derechos de los animales y, del otro, el consistente en reconocer que los animales tienen derechos en sentido débil, distinguiendo entre usos 'esenciales' y usos 'no esenciales'.

En el primero de ellos, desde la comunidad de iguales se defiende que los animales tienen derecho a la vida, a la libertad y a no ser sacrificados arbitrariamente; por ello, no distinguen los derechos humanos y los derechos de los animales no humanos, ya que, con base en una postura biocéntrica, los derechos de todos los seres vivos merecen ser respetados. Este planteamiento rechaza considerar a los animales como propiedad de los humanos que los tienen a su total disposición para fines de diversión, salud o utilidad laboral, y aboga por suprimir la explotación a la que están expuestos y prohibir la tortura y el maltrato, muchas veces amparados por ancestrales costumbres culturales o modernas técnicas de experimentación científica.

Un nivel de protección máximo en esta línea es el desarrollado en el 'Proyecto Gran Simio', dentro de la declaración de la comunidad de los iguales, donde se defiende la equiparación de determinados principios o derechos morales fundamentales de seres humanos y simios (chimpancés, gorilas y orangutanes), para reconocerles tres derechos: vida, libertad y prohibición de la tortura. El derecho a la vida debe protegerse a todos los miembros de la comunidad de iguales negando la posibilidad de darles muerte, salvo en circunstancias excepcionales como puede ser en defensa propia; el derecho a la libertad impide la privación arbitraria de su libertad, por eso, si se les aprisiona sin previo proceso legal tienen derecho a la liberación inmediata, a menos que sea por su propio bien o resulte necesario para proteger a la comunidad de algún miembro peligroso, siempre que se puedan defender ante un tribunal por medio de alguien que les represente. Por último, la prohibición de tortura impide infligir dolor grave de manera deliberada a cualquier miembro de la comunidad de iguales sin ningún motivo y aunque sea en beneficio de otros (Cavelier y Singer, 1998, p. 12).

Lo que justifica esta protección especial dispensada a los simios son sus facultades mentales y una vida emotiva suficiente como para incluirlos en la comunidad de iguales junto a los seres humanos, sin que sea un obstáculo que no 
puedan defender por sí mismos sus derechos, pues tampoco pueden hacerlo los menores de edad o los discapacitados, bastando que lo hagan sus representantes legales.

Aquí, el grado de protección se eleva, porque los derechos de los animales se protegen por sí mismos y al margen de su relación con los hombres, reconociéndoles el mismo derecho a la dignidad que a la especie humana. La equiparación entre los derechos de las personas y los derechos de los animales encuentra algunas dificultades jurídicas, ya que todos los animales no pueden tener los mismos derechos; por eso, a veces se propone distinguir la clase de derecho reconocido en función del tipo y características del animal, para evitar la comparación entre los ataques a insectos, primates, animales domésticos o animales salvajes. Además, existen derechos que requieren una capacidad volitiva o de comunicación de la que carecen los animales, lo cual les impide su ejercicio e, incluso, otros son incompatibles con la naturaleza animal (Muñoz, 1999, p. 75), lo que aconseja seleccionar los derechos que pueden reconocerse a los animales.

Esta idea da paso a una postura de biocentrismo moderado en el que se reconoce la dignidad de ciertos animales como derecho a no ser objeto de propiedad y, con ello, a no ser explotados ni maltratados. De esta forma, no todos los animales tienen los mismos derechos, ni se les reconocen los mismos que a los seres humanos (De Lucas, 2009, p. 16); algunos animales son sujetos de derechos por sí mismos, porque tienen intereses propios y capacidad de experimentar placer, dolor o sufrimiento, es decir, gozan de una especie de derecho al bienestar. Esa capacidad de sufrir de algunos animales les confiere el derecho a no ser considerados como propiedad -no están sujetos a la disponibilidad absoluta de quien ejerce el dominio- $y$, en consecuencia, no pueden ser objeto de maltrato.

Tal reconocimiento no evita que puedan surgir conflictos entre los derechos de los animales y los derechos de los seres humanos, mismos que deberán resolverse atendiendo a la ponderación de intereses que valore la prevalencia de los intereses primarios sobre los secundarios recíprocamente, es decir, dando preferencia a los intereses primarios de los seres humanos sobre los intereses secundarios de los animales, pero también en sentido inverso (De Lucas, 2009, p. 17).

A partir de ese momento surgen dos vías: abogar por la supresión paulatina -y preferentemente ligada a la educación- de cualquier sacrifico y maltrato animal no justificado en intereses primarios de los seres humanos o, bien, optar por la prohibición legal de cualquier vulneración del derecho más básico de los animales que disponen de capacidad de sentir, que es el derecho a no ser tratado como un objeto de propiedad, para evitar el maltrato y la explotación más allá de los usos esenciales para la sociedad.

Esta postura tiene de positivo que reconoce un determinado nivel de protección penal autónomo a los animales, si bien su inconveniente es que la amplitud de los términos 'usos esenciales o beneficiosos para la sociedad' puede generar cierta inseguridad jurídica por estar expuesto no sólo a criterios culturales y sociales diversos, sino, también, a su concreción por los aplicadores del derecho. 


\section{Delimitación del bien jurídico protegido.}

Las normas administrativas, bien sean municipales, regionales, estatales o internacionales que protegen a los animales se suelen basar, fundamentalmente, en la tutela de su bienestar y, las penales, en tanto los delitos correspondientes deben ubicarse en el Código Penal, presuponen la determinación del bien jurídico salvaguardado.

Una posibilidad es su asignación al bien jurídico medio ambiente y recursos naturales, algo que no es correcto cuando se trata de animales domésticos o similares, ya que no existe relación entre esas conductas y la protección del equilibrio del ecosistema. Otra alternativa, también frecuente, es referirlos al sentimiento de compasión de los seres humanos, lo cual, además de ignorar el sufrimiento del animal, prioriza las exigencias de deber jurídico sobre la tutela de derechos. La postura que supera a las mencionadas y se corresponde mejor con el reconocimiento de derechos propios de los animales es la relativa al derecho al bienestar, entendido como ausencia de sufrimientos innecesarios, de tal forma que protege a cada animal-considerado aisladamente- de las conductas de maltrato que afectan su vida, salud, integridad y dignidad (Hava, 2011, p. 278).

En el caso de España, la inclusión del art. 337 del Código Penal que regula estos delitos en el capítulo dedicado a la 'protección de la flora, la fauna y los animales domésticos' es anacrónica, porque la evolución legislativa del delito ha terminado tutelando a otras muchas categorías de animales más allá de los domésticos; por ello, sería más adecuado que se llamara 'delitos contra los derechos de los animales'. Siguiendo esta línea, la denominación 'delitos contra los animales' utilizada en Colombia tiene un alcance más amplio y, con ello, más acorde con su contenido.

Cuando se introdujo el delito, la doctrina española discutía si el bien jurídico consistente en proteger la vida o integridad de los animales domésticos debía tener naturaleza penal; por ello, un importante sector ${ }^{2}$ abogaba por su consideración como conducta leve, o en su caso, infracción administrativa, ya que elevarlo a la categoría delictiva podría vulnerar el principio de proporcionalidad que exige una correspondencia entre la gravedad de las conductas y la naturaleza y entidad de las sanciones penales.

Otros problemas apuntados fueron la vulneración del carácter de ultima ratio, la ausencia de justificación punitiva en la Exposición de Motivos cuando se incorporó al Código Penal y en las sucesivas reformas, la suficiencia de las sanciones administrativas por su mayor eficacia e, incluso, la instrumentalización política de estas conductas que llegan al derecho penal con una finalidad meramente simbólica (Martínez-Buján, 2004, p. 764; Quintero, 2004, p. 1769).

${ }^{2}$ Martínez-Buján (2004 p. 764); Muñoz (2007, p. 589) y Córdoba y García (2004, p. 1468). Recientemente, y ya tras la reforma, con la nueva regulación que amplía los delitos de maltrato animal, Muñoz sigue entendiendo que es un bien jurídico difícil de determinar (2015, p. 518), Martínez-Buján (2015, p. 566) lo considera discutible y Queralt (2015, p. 1002) lo rechaza, pese a considerar que se trata de conductas inmorales. 
Frente a estas críticas, ha de admitirse que, sin llegar a la consideración de una equiparación de derechos entre personas y animales, existen ciertas conductas de maltrato animal que, por su gravedad y el sufrimiento producido a los animales como seres vivos, merecen ser castigados por el derecho penal, pues la necesidad de tutela justifica su penalización, siempre que se respete la perspectiva del principio de proporcionalidad respecto de otras figuras que afectan a los seres humanos. En este sentido, el bien jurídico protegido en las conductas de maltrato a los animales sería el bienestar animal frente al maltrato y el sufrimiento, manifestado en la integridad física, psíquica y salud de los animales como seres vivos, atendida su capacidad de sentir emociones y de sufrir ${ }^{3}$, y el derecho a no ser maltratados ${ }^{4}$.

Lo anterior supone considerar que los animales forman parte de la biodiversidad o variedad de organismos vivos -elemento integrante del medio ambiente-, lo que los dota de una autonomía valorativa quejustifica el rechazo a su consideración como objeto de propiedad y su consecuente y sesgada consideración antropocéntrica, que sólo ve en el maltrato la afección de los sentimientos de los humanos que las presencian.

\section{Conducta típica: ámbito de lo punible en el maltrato animal}

Partiendo de un biocentrismo moderado que reconoce la dignidad de ciertos animales, entendida como el derecho de estos últimos a no ser objeto de propiedad $\mathrm{y}$, por consiguiente, a no ser explotados ni maltratados, son varias las conductas que pueden ser prohibidas y que se agrupan en torno a la afectación causada a la salud y la integridad del animal. Es importante destacar que todas ellas surgen alrededor del maltrato, es decir, la muerte o las lesiones sin más no suelen ser castigadas si no van asociadas a una conducta de maltrato.

\section{Conductas básicas de maltrato cruel.}

El maltrato, como menoscabo a la salud, es la conducta más compleja de determinar teniendo en cuenta los usos y costumbres tradicionales que surgen de la convivencia de los seres humanos con los animales; por ello, a la hora de delimitar la tipicidad de una conducta delictiva, hay que valorar, en virtud de la adecuación social, la posibilidad de excluir aquellas conductas socialmente aceptadas por estar inmersas en los usos sociales habituales y, en las restantes, valorar si la entidad de los hechos justifica su penalización o si basta con la educación y la prevención como instrumentos para erradicar ciertas prácticas humanas con los animales.

Con esta indeterminación, el término maltratar abre un amplio abanico de conductas socialmente aceptadas que pueden presentar cierta gravedad en algunos casos, p. ej., el mantenimiento de animales en instalaciones inadecuadas por sus

${ }^{3}$ Como señales inequívocas de sufrimiento de los animales se citan los gemidos, vocalizaciones intensivas, resistencias, temblores, convulsiones, otros signos externos de aflicción e incluso algunos sin manifestación externa (Mosterin, 1995, p. 48).

${ }^{4}$ Ríos (2008), admite la integridad física y psíquica de los animales como bien jurídico penal (p. 12). 
condiciones higiénico-sanitarias, someterlos a trabajos que les causen una fatiga excesiva, limitarles la libertad atándolos de forma permanente, suministrarles sustancias que alteren gravemente su salud, utilizar determinadas técnicas cinegéticas o gastronómicas que implican torturas o sufrimientos, la experimentación animal para ensayos de productos cosméticos y la realización de operaciones de comercio ilegal. Todas las anteriores deben ser interpretadas judicialmente para determinar si son maltratos con relevancia penal, teniendo en cuenta que, en muchas ocasiones, el debate es sobre la necesidad o no del maltrato para los usos esenciales humanos.

Otras conductas, empero, entran sin ninguna duda dentro del concepto de maltrato por su mayor gravedad; tal es el caso de castigar, agredir, golpear, mutilar, quemar o producir cualquier tipo de sufrimiento físico o psíquico manifestado en magulladuras, heridas, hematomas o contusiones.

Para evitar la indeterminación y la confusión de dicho término, en Argentina (Ríos, 2008, p. 14) se realiza un listado de conductas consideradas como maltrato, v. gr., no alimentar suficientemente a los animales domésticos cautivos, azuzarlos provocándoles dolores innecesarios, hacerles trabajar de forma excesiva, drogarlos para estimularles; $y$, además, se considera cruel un listado más amplio en el que hay conductas como mutilarlos, intervenirlos quirúrgicamente sin anestesia o las torturas o males innecesarios. La enunciación puede, en algunos casos, facilitar la interpretación, pero conlleva los inconvenientes de los listados excesivamente casuísticos que, en virtud de las exigencias del principio de legalidad, dejan fuera a todo lo que no esté expresamente señalado en el texto.

Antes, el Código Penal español exigía que se tratara de un maltrato injustificado y cruel; ahora sólo exige que sea cruel, lo que evita la incongruencia de entender que pueda haber maltratos justificados, pero mantiene la contradicción de admitir que puede haber maltratos no crueles. Esto obliga, por una parte, a realizar dudosas clasificaciones del maltrato derivadas de la gravedad de la violencia ejercida $\mathrm{y}$, por otra, a diferenciar hechos aislados de hechos prolongados y reiterados en el tiempo como signo de sufrimiento animal, generando frecuentes problemas de interpretación.

En España, la conducta genérica de maltrato desligada de sus resultados se aplica sólo en dos supuestos: primero, cuando se trata exclusivamente de animales domésticos, en cuyo caso no son necesarios resultados ulteriores, siendo una conducta de mera actividad destinada a proteger especialmente a los animales domésticos en cualquier lugar en el que se encuentren y, segundo, cuando el maltrato sea de cualquier animal, pero en espectáculos públicos no autorizados legalmente, con lo que se trata más bien de una conducta que infringe una norma administrativa destinada a regular el maltrato de animales como un espectáculo para el deleite de los seres humanos. Con ello se da entrada a dos elementos básicos de estos delitos, que serán desarrollados más adelante, cuales son, el diferente nivel de protección entre los distintos tipos de animales y los espectáculos públicos que, pese a suponer un maltrato animal, están autorizados por la ley. 
Los maltratos, en principio, pueden ser físicos o psíquicos, pero en todo caso deben suponer un sufrimiento para el animal, lo que obliga a distinguir entre conductas omisivas de mero abandono -que son conductas diferentes que no van ligadas a resultado- y conductas en las que el abandono pone en peligro la vida e integridad del animal.

\section{Maltrato con resultados sobre la vida y la integridad: lesiones, explotación sexual y muerte.}

En este caso el maltrato de animales, caracterizado por una mayor universalidad porque se dirige a más especies de animales, reúne tres elementos comunes: que se produzcan resultados específicos lesivos para la salud, que se pueda llevar a cabo por cualquier medio o procedimiento y que sea injustificado. Los posibles resultados son: lesiones que menoscaben gravemente la salud, sometimiento a explotación sexual y muerte del animal.

\section{Maltrato que cause lesiones que menoscaben gravemente la salud.}

El concepto de lesión animal es específico y no coincide con el de personas; por ello, se debe regir por términos veterinarios. En las personas se valora que, además de una primera asistencia facultativa, se necesite objetivamente para su sanidad tratamiento médico o quirúrgico, entendiendo por tal los cuidados reiterados indicados por un médico, dirigidos a curar una enfermedad; aquí podría ser algo similar, siempre teniendo en cuenta los criterios anteriormente señalados.

En el caso de los animales, las lesiones deben menoscabar gravemente la salud, lo que implica una afección de relevancia tanto para la integridad física como psíquica. Como son escasos los tratados de veterinaria legal, algunos autores, siguiendo a Higuera (1998, p. 350), formulan una clasificación de lesiones animales que incluye las siguientes: contusiones (equimosis, hematomas y magullamientos), conmociones, distensiones (lesiones en músculos, ligamentos, tendones), luxaciones y fracturas, mutilaciones y quemaduras. En el caso de las lesiones psíquicas, se pueden entender aquellas que provoquen el sufrimiento interno de un animal, como seres que pueden sentir, materializado en el dolor, el miedo, la angustia o el estrés.

\section{Maltrato que someta al animal a explotación sexual.}

Esta modalidad es nueva -se ha incorporado en la reforma de 2015- y parece referirse a la realización de actos sexuales con animales, teniendo la consideración de maltrato por la explotación que conllevan y los daños que les producen. Por lo tanto, no se refiere a la comisión de cualquier acto sexual con animales, lo que quedaría dentro de la ética personal y no de la tutela penal. La zoofilia ${ }^{5}$ no puede ser

\footnotetext{
${ }^{5}$ Apunta Manzanares (2015, p. 285) que son varios países los que han incluido la zoofilia como conducta delictiva, como es el caso de Suecia, Alemania, Holanda o Méjico. Sin embargo Muñoz (2015, p. 518), señala que la zoofilia como tal no debe estar en el derecho penal.
} 
constitutiva de delito en todo caso, sino sólo cuando supone un maltrato injustificado, por eso el término explotación no es muy adecuado, porque parece indicar comercio o difusión, cuando el sentido del delito parece ser la instrumentalización del animal en el acto sexual como una forma de maltrato injustificado y no que ello tenga que ser difundido o comercializado.

En este supuesto, aunque se aprecia una diferencia esencial entre Colombia y España (en el primero se castiga la realización de todo tipo de acto sexual con animales, mientras en el segundo ha de haber una explotación sexual), la exigencia del maltrato, común a ambos países, puede llevar a las mismas conclusiones, es decir, a no incriminar todo tipo de actividad sexual con animales, sino únicamente aquella que se pueda entender como un maltrato.

\section{Maltrato que cause la muerte.}

La muerte debe ser el resultado del maltrato injustificado, siendo indiferente que sea inmediata o después de un cierto tiempo, en tanto se acredite el nexo causal entre la conducta y el resultado muerte. Además, la muerte puede ser consecuencia de una conducta activa -golpear- $\mathrm{u}$ omisiva -descuidar las atenciones y cuidados-; por eso, la muerte por inanición estaría dentro de este supuesto y no en el correspondiente al abandono.

Al tratarse de un tipo de resultado, la acción es el maltrato y el resultado es la muerte, lesiones físicas o explotación sexual, pero sin olvidar que la una y el otro han de estar unidos por una relación de causalidad. Producir la muerte por otros actos - un atropello- o si, pese al maltrato, la muerte es consecuencia de otra causa -enfermedad, asistencia errónea, etc.-, tales supuestos quedan por fuera del tipo, ya que la muerte, lesiones o explotación sexual deben estar vinculadas al maltrato. Las formas imperfectas son posibles, por consiguiente, la acción dirigida a matar o lesionar a un animal sin conseguirlo, por causas ajenas a la voluntad del sujeto, merecerán la calificación de tentativa, $v$. gr., si el animal es atendido y se logra salvar su vida o no se producen las lesiones.

La expresión por cualquier medio o procedimiento indica que el maltrato puede ser activo, p. ej., a través de golpes, u omisivo, como dejar de alimentar, dejar a la intemperie, no prestar los cuidados necesarios, etc., lo que, teniendo en cuenta que se trata de un delito de resultado, da lugar a la comisión por omisión. Con ello deben distinguirse estas conductas de las de mero abandono: la diferencia reside en que en la comisión por omisión de este delito se produce la muerte, lesiones o explotación sexual como consecuencia del maltrato por quien es garante del animal (Córdoba, 2004, p. 1471), mientras que, en el abandono, sólo se pone en peligro su vida o integridad, es decir, en el primer delito se exige resultado material mientras que el de abandono es una figura de mera actividad en cuanto a la conducta y de peligro para el bien jurídico.

Que el maltrato sea injustificado debe ser entendido desde la intervención mínima, por eso el maltrato animal no se puede equiparar al de los humanos 
(González, 2015, p. 1082) y ha de limitarse a dos supuestos: que no sea inherente a la condición de animal (González, 2015, p. 1082 y Martínez, 2015, p. 566), por ejemplo, cargar peso o que se trate de supuestos legalmente justificados. Si hay alguna autorización legal el maltrato no será injusto, en este sentido se pueden entender como tal las corridas de toros, los actos propios de experimentación científica o los sacrificios llevados a cabo en los mataderos, siempre con las correspondientes previsiones legales, pues la normativa vigente que regula las actividades con animales prohíbe expresamente los sufrimientos. Otro supuesto puede ser la legítima defensa, por ejemplo, quien se defiende frente al ataque de un perro de gran tamaño y raza peligrosa.

\section{Maltrato agravado por los medios utilizados o las formas de comisión.}

Son diversas las agravaciones que se pueden plantear en la protección penal frente al maltrato animal. En España las hay de tres tipos: a) las referidas a los medios comisivos: uso de armas, instrumentos, objetos, medios, métodos o formas concretamente peligrosos, y al ensañamiento como aumento innecesario del sufrimiento del animal, lo que exige un dolo específico de hacer sufrir 6 ; b) las agravaciones por el resultado: lesiones que producen la pérdida o inutilidad de sentido, órgano o miembro principal; c) si se realizan los hechos en presencia de menores.

En Colombia, las circunstancias de agravación son muy similares, si bien se añaden dos de singular importancia: la primera, si los hechos se producen en lugar público, lo que parece recoger su afección a los sentimientos de las personas, y, la segunda, si los realizan servidores públicos, lo que no debería justificar una mayor sanción, salvo que se trate de una conducta relacionada con el ejercicio de su empleo público.

\section{Maltrato cruel de cualquier animal en espectáculos no autorizados legalmente.}

El maltrato de cualquier tipo de animal en espectáculos no autorizados legalmente supone que existen espectáculos autorizados donde es posible que se realicen maltratos, e indica, a su vez, que si los espectáculos no están autorizados el maltrato será delictivo. Esto permite diferenciar dos tipos de espectáculos con animales: los no autorizados y los autorizados; entre los primeros se pueden citar, en España, las peleas de gallos o las peleas de perros y, entre los segundos, el circo que incluya espectáculo con animales o las corridas toros, si bien, como luego se indica, es posible encontrar distinto nivel de protección y prohibición en las diferentes ciudades y Comunidades Autónomas.

Anteriormente, la razón de castigar estos espectáculos no autorizados era que se llevaran a cabo en público y, por lo tanto, debido a su proyección a terceros, e incluso limitándolo a animales domésticos. En la actualidad, se suprime la necesidad de que sea en público, pero el espectáculo, aun siendo clandestino, requiere presencia de personas por definición; además, lo amplia a todo tipo de animales.

${ }^{6}$ Este elemento subjetivo inherente al ensañamiento provoca muchas dificultades para apreciar que sea algo diferente al maltrato cruel, Muñoz (2007, p. 353). 
Con ello, esta figura residual descarta que el interés protegido sea la compasión que despierta en quienes los presencian y refuerza que el interés objeto de protección exclusiva es el derecho de los animales a no ser maltratados.

Un problema específico de la autorización de espectáculos es su contenido cultural y social, lo que provoca que haya multitud de manifestaciones diferentes en función del lugar donde se lleven a cabo, por ello, es posible que una misma práctica sea legal en un lugar e ilícita en otro. Es lo que sucede con las peleas de gallos o las corridas de toros en España, cuya situación paradójica es que una misma conducta, según el lugar donde se lleve a cabo, pueda o no ser considerada delito.

Como ejemplo punitivo, la Ley 22 de 2003 de protección a los animales de Cataluña prohibió el uso de animales en peleas y espectáculos u otras actividades que pudieran ocasionar sufrimiento, burlas o tratamientos antinaturales, y también las que pudieran herir la sensibilidad de las personas que los contemplen, como peleas de perros o de gallos, matanzas públicas de animales o tiro de pichón. Además, tras un periodo transitorio, finalmente se prohibieron también las corridas de toros en esta Comunidad Autónoma (Ley 28 de 2010 del Parlamento de Cataluña) $\mathrm{y}$ en otras ciudades y provincias se han impulsado iniciativas similares.

Como ejemplo permisivo, la Ley 8 de 1991 de protección a los animales de Canarias permite las peleas de gallos, siempre que se prohíba la entrada a menores de dieciséis años, que las instalaciones donde se celebren peleas tengan, por lo menos, un año de antigüedad al momento de la entrada en vigor de la Ley, salvo las que se construyan en sustitución de aquellas y, por último, que las instalaciones o lugares donde se celebren las peleas sean recintos cerrados. En este caso se trata de una práctica ilegal en el resto de España y, por lo tanto, limitada a las Islas Canarias, donde gozan de una fuerte tradición.

La prohibición o no de estos festejos populares es compleja, porque en ella confluyen elementos ideológicos, culturales y de tradición histórica con decisiones políticas sobre temas en los que, para evitar la fractura social, se producen situaciones contradictorias y difíciles de comprender. Como ejemplo de ello, en España va creciendo el rechazo social a las corridas de toros, quizá porque no deja de ser un espectáculo que, al requerir una plaza de toros se celebra normalmente en ciudades grandes, y para un público solvente, específico y entendido, pero no ocurre lo mismo para otras celebraciones que utilizan toros o vacas en carreras populares, provocándoles daños por los golpes recibidos o las bolas de fuego que se colocan en sus astas (bous al carrer, toro embolado...). La razón es que estas últimas están asociadas a las fiestas locales de numerosos municipios y tienen un carácter popular muy generalizado por ser de acceso libre y gratuito, lo que facilita que se pueda acudir y participar de forma directa. La alternativa a esta contradicción se está intentado salvar con la regulación en estos últimos espectáculos de normas de buenas prácticas que garantizan que no haya maltrato de los animales e incluyendo la supervisión obligatoria de un veterinario antes y después del festejo, sin llegar a impedir la utilización de animales para la diversión. 


\section{Los animales como objeto de protección}

Unos de los temas más discutibles en la tutela de los derechos de los animales es si la misma se dirige a todos los animales por igual o, por el contrario, si se establecen distintos niveles de protección en función de la proximidad de los animales a los seres humanos y a la capacidad que éstos tengan de sentir.

La reforma española de 2015 ha ampliado de una forma espectacular las tipologías de animales protegidos por la norma penal, teniendo en cuenta que, cuando se introdujo en 1995, la figura delictiva se centraba básicamente en el maltrato a los animales domésticos. Los defensores de los derechos de los animales, aunque reconocen que todos ellos tienen derechos, admiten diferencias en su amplitud e importancia, ya que la particularidad de los domésticos es que su relación con la especie humana se ve alterada por su sometimiento, lo cual los hace participes de sus hábitos de convivencia (Salt, 1999, p. 49).

\section{Animales domésticos o amansados.}

Las razones para la especial protección de los animales domésticos se pueden encontrar en su mayor capacidad de sufrimiento por su cercanía a los humanos y por las incuestionables ventajas o utilidades que les reportan en su vida cotidiana (Hava, 2011, p. 293); pese a ello, el primer obstáculo es concretar dicho término, dada la falta de unanimidad doctrinal en este sentido. La solución se puede encontrar en las normas administrativas, si se entiende que nos encontramos ante una ley penal en blanco o, bien, dejarlo a la discrecionalidad judicial; sin embargo, la falta de uniformidad en las leyes administrativas reguladoras de los derechos de los animales dificulta esta tarea y, por eso, mientras el Código Penal español sólo aludía a los animales domésticos, su concreción se dejó a los órganos judiciales, lo que tampoco era satisfactorio, porque daba lugar a pronunciamientos contradictorios.

La discusión sobre el alcance de la expresión animales domésticos se centraba en determinar si se refería sólo a los animales de compañía o mascotas, o también a los de renta o de granja, ya que doméstico, en principio, es todo animal que vive bajo el control humano con independencia de que lo sea para hacer compañía o participar de la producción y la cría. La Circular 7 de 2011 de la Fiscalía General del Estado 'sobre criterios para la unidad de actuación especializada del Ministerio Fiscal en materia de medio ambiente y urbanismo' resolvió este tema señalando que animales domésticos son los que viven en compañía de las personas, lo que incluye a las mascotas, los animales de granja y los destinados a la carga. En las mascotas no se da ninguna actividad lucrativa, pues se convive con ellos por placer; los de granja o renta conviven y son criados para la producción de alimentos u otros beneficios económicos; y los destinados a carga son los que se utilizan para el trabajo, razones todas ellas que justifican una especial protección.

En la reforma del Código Penal de 2010 se añadió a los animales amansados, entendiendo como tales aquellos que, siendo silvestres o salvajes, han sido 
dominados por el hombre para acostumbrarlos a su compañía, lo que incluye animales exóticos como iguanas o serpientes, pero deja sin despejar la duda de si alcanza a los amansados que viven en cautividad.

\section{Animales de los que habitualmente están domesticados.}

Esta nueva categoría puede servir para incluir a aquellos animales que, siendo domésticos, viven en total libertad, ejemplo de ello pueden ser los gatos salvajes que no viven bajo el control de ningún ser humano. Su exclusión anterior derivaba de un concepto restringido de animal doméstico que dejaba fuera a los animales abandonados, vagabundos o callejeros, pese a ser estos precisamente los que más protección necesitan por estar expuestos a un mayor riesgo y recibir el mayor número de agresiones y torturas.

\section{Animales que temporal o permanentemente viven bajo control humano.}

En este caso se trata de aquellos animales no domésticos, ni siempre pacíficos, que por convivir con algunas personas, se les dota de esta protección, por ejemplo, los animales del zoológico que, con independencia de que sean más o menos peligrosos, son tutelados por su convivencia con las personas.

\section{Cualquier animal que no viva en estado salvaje.}

De forma residual, esta referencia a cualquier animal no salvaje intenta dejar claro que sólo aquellos animales fieros o salvajes que vagan libremente y se capturan por la fuerza a través de la caza o pesca, quedan fuera de la tutela penal frente al maltrato.

Esta fórmula da lugar a un objeto material muy amplio, que solo deja fuera de la tutela frente al maltrato a los animales fieros o salvajes, salvo que se trate de un maltrato cruel y se realice en un espectáculo público no autorizado, en cuyo caso se trata de un delito diferente que solo contempla la conducta básica de maltrato cruel y no las cualificadas por el resultado. Esta ampliación evita la impunidad de algunas conductas, $v$. gr., el maltrato a una fiera domesticada o amansada para trabajar en el circo que no se produzca durante un espectáculo, sino en las dependencias privadas por su cuidador $\mathrm{u}$ otra persona diferente, en tanto queda dentro del supuesto de animales que viven bajo el control humano.

La terminología empleada en Colombia sugiere un objeto de protección más amplio, por cuanto la referencia a animal doméstico, amansado, silvestre vertebrado o exótico vertebrado, incluye también a los silvestres o salvajes y sólo deja fuera a los invertebrados.

\section{Autorizaciones legales}

Reconocido el derecho al bienestar de todos los animales, aunque la tutela penal deje fuera a los salvajes, se parte de la base de que los animales no deben ser considerados como objeto de uso y explotación, siendo necesario delimitar el alcance 
de la autorización legal que permite realizar conductas lesivas para los derechos de los animales.

Los límites legales del respeto a los derechos de los animales se deben diseñar desde el plano del conflicto de intereses y, a tono con ello, ha de prevalecer el de mayor valor sobre el de menor, lo que invita a distinguir entre los usos esenciales para los humanos que puedan autorizar ciertos daños sobre los animales, de aquellos casos en que, al no ser esenciales para los humanos, es factible prescindir de ellos en aras a salvaguardar los derechos de los animales. En tal virtud, sólo las prácticas que supongan un beneficio para la sociedad podrían ser autorizadas (Ríos, 2008, p. 8).

Entre los usos esenciales se pueden destacar la investigación biomédica o científica y la alimentación humana donde se imponen los derechos de los humanos sobre los de los animales, lo que no impide regular sus procedimientos para evitar daños innecesarios. Los usos no esenciales incluyen todos los referentes al placer o divertimento de los humanos, como los espectáculos y las prácticas deportivas, donde debe prevalecer el derecho de los animales a no sufrir maltrato y, por ello, autorizarlos legalmente puede quebrar el principio de la preponderancia de intereses.

A la dificultad para determinar los supuestos que quedan comprendidos o no dentro de las autorizaciones legales debe añadirse que dichas autorizaciones son, normalmente, reguladas por normas administrativas -se trata de leyes penales en blanco-. Como consecuencia de ello, en lo formal, plantean el problema de las dificultades derivadas de la dispersión legislativa y, en lo material, proponen dudas a la hora de justificar la intervención penal por incumplimientos administrativos.

En líneas generales, los eventos más frecuentes son los de experimentación científica, el sacrificio en mataderos y las fiestas populares.

\section{Experimentación científica.}

La 'Declaración Universal de los derechos del animal' (Organización de las Naciones Unidas, 1977) prohíbe cualquier experimentación médica, científica, comercial o de cualquier otro tipo que implique un sufrimiento físico o psicológico del animal.

En España, el Real Decreto 53 de 2013, que regula la protección de animales utilizados en experimentación y otros fines científicos, exige adoptar cuidados adecuados y evitar que se les cause innecesariamente dolor, sufrimiento, angustia o lesión prolongados, reduciendo al mínimo el número de animales utilizados y aplicando métodos alternativos. En este decreto, de ámbito nacional, se reglamentan las condiciones generales de alojamiento y manejo, y se reitera la prohibición de causar dolor, sufrimiento o angustia innecesarios a los animales utilizados para la experimentación, siendo obligatoria la anestesia, salvo que la misma sea traumática para el animal o incompatible con la investigación. Para el cumplimiento de dichas normas se crea en los centros públicos un comité ético de bienestar animal. 


\section{Sacrificio de animales en mataderos.}

Las Directivas europeas y normas administrativas nacionales prohíben los métodos crueles, pues reclaman que los animales no sufran ni sientan dolor durante el sacrificio. La Ley 6 de 2013 regula la explotación, transporte, experimentación y sacrificio de animales estableciendo una serie de principios sobre el cuidado animal con un régimen común de infracciones y sanciones, en orden a garantizar su cumplimiento; entre estas se pueden destacar el sacrificio o muerte de animales en espectáculos públicos no autorizados, utilizar a los animales en peleas, realizar mutilaciones no permitidas o utilizar perros o gatos abandonados para experimentación, entre otras.

\section{Fiestas populares.}

Las fiestas populares requieren una mención especial, por la gran aceptación que tienen en algunas zonas de España las diversiones que producen sufrimiento o dolor a los animales, como puede ser el toro embolado, las vaquillas o las corridas de toros.

La regulación de estos supuestos se apoya sobre dos premisas: algunos espectáculos públicos con animales están autorizados legalmente y, por lo tanto, en ellos se resuelve el conflicto de intereses a favor de los humanos, pero, si se llevan a cabo espectáculos que no están autorizados o se llevan a cabo sin cumplir las formalidades legales, la conducta será delictiva.

En el primer caso, la regulación legal de festejos o actividades de entretenimiento en los que se utilicen animales debería preservar el bienestar de estos, sin permitir cualquier acto de maltrato; sin embargo, como muchas de las mencionadas se aferran a la raigambre popular y a la permanencia de tradiciones ancestrales, las posibles soluciones son su eliminación progresiva a través de la educación y la sensibilización social o, bien, directamente por la vía de la sanción legal. Ejemplos localizados de lo primero ha habido en los últimos años a través de prohibiciones establecidas por los propios Ayuntamientos que han eliminado fiestas populares por la controversia que suscitaban, es el caso de la supresión de la tradición de tirar a una cabra desde un campanario en la localidad de Manganeses de la Polvorosa en Zamora, y de la prohibición de las corridas de toros y el uso de animales en circos en diversos municipios como Barcelona y Palma de Mallorca.

Siguiendo esta línea, las exenciones de pena previstas en la legislación de Colombia son las autorizaciones legales de cuidado, cría, reproducción, adiestramiento, y mantenimiento de animales, el procesamiento relacionado con la producción de alimentos y las actividades de entrenamiento para competiciones legalmente aceptadas, con lo cual no alcanzaría a las fiestas populares que se regirían por las reglas generales de prohibición del maltrato causante de muerte o lesiones (parágrafo $1^{\circ}$ del art. 339B). Lo anterior, sin perjuicio de la remisión que hace la propia Ley 1774 de 2016 (parágrafo $3^{\circ}$ del art. 339B) al art. $7^{\circ}$ de la Ley 84 de 1989, referido a la autorización del rejoneo y el coleo, las corridas de toros, las 
novilladas, las corralejas, las becerradas y las tientas, así como las riñas de gallos y los procedimientos utilizados en esos 'espectáculos', declarada exequible por la Corte Constitucional mediante la Sentencia C-666 de 2010.

\section{Conclusiones}

Las nuevas leyes que amparan los derechos de los animales son una muestra del cambio sociocultural experimentado en las sociedades modernas que no sólo reconocen derechos de especies no humanas, sino que sancionan las conductas que los vulneran.

La consideración del maltrato animal como nueva conducta delictiva presenta una especial complejidad, dado que, en muchos casos, se trata de transformar costumbres culturales fuertemente arraigadas en conductas susceptibles de sanción penal, lo que implica superar el relativismo cultural -según el cual toda pauta cultural debe ser respetada como manifestación de la expresión colectiva-por una nueva ética de convivencia social en la que las vejaciones, sufrimientos y daños innecesarios a los animales pueden y deben ser erradicados.

La convivencia pacífica entre seres humanos y animales no puede impedir que se presenten conflictos entre ambos; por eso, los derechos de los animales podrán ceder en orden a salvaguardar intereses esenciales para la vida humana como la alimentación o la salud, pero no para otros secundarios como la diversión o el espectáculo. Esa es la razón que explica que la tutela a los derechos de los animales haya empezado por el maltrato cruel e injustificado y por los espectáculos públicos no regulados; sin embargo, la evolución social nos hará saber si esto es sólo un primer paso y la ética de respeto al mundo animal tenderá a rechazar todo tipo de daño a los animales, e incluso, todo tipo de instrumentalización.

Como anteriormente se ha señalado, el respeto a los derechos de los animales no es sólo una figura de reciente recepción en el plano jurídico, es una transformación de la ética social y la cultura popular. En tal virtud, toda la responsabilidad de este cambio no puede recaer en el ámbito punitivo, sino que la educación en valores de respeto al mundo animal y la prevención de conductas generadoras de daños innecesarios a los animales es, en general, el complemento imprescindible para una nueva concepción de convivencia de las especies humana y animales.

En relación con la penalidad, aunque se ha discutido su levedad, es importante destacar que la sanción elegida en el Código penal español, y en Colombia ocurre algo similar, en ningún caso supera los dos años de prisión, lo que permite suspender la ejecución sin ingresar en prisión, imponiendo en su lugar la obligación de realizar programas de tratamiento de respeto a los animales. Además, todas las conductas se castigan con la inhabilitación para el ejercicio de profesión, oficio o comercio que tenga relación con los animales y para la tenencia de animales, salvo la última en la que es opcional, lo que refleja una opción por la prevención y la educación más allá de una sanción exclusivamente punitiva. 


\section{Referencias}

Cavalieri, P. y Singer, P. (1998). El proyecto gran simio. La igualdad más allá de la humanidad. (Trad. C. Martín y C. González). Madrid: Trotta.

Cobo del Rosal, M. (Coord.). (2005). Derecho Penal. Parte Especial. (2 ${ }^{\mathrm{a}}$ ed). Madrid: Dykinson.

Córdoba, J. y García, M. (Coords.). (2004). Comentarios al Código Penal. Parte Especial (T. I). Madrid: Marcial Pons.

Cuerda, M. (2015). Maltrato y abandono de animales (art. 337 y 337 bis). En J González (Dir.). Comentarios a la reforma del Código Penal de 2015 (pp. 1073-1084). (2 ed.). Valencia: Tirant lo Blanch.

De Lucas Martín, J. (2009). En el bicentenario de Darwin ¿derechos de los animales no humanos? La barrera de la dignidad Teoría E Derecho, (6), 7-18.

Hava, E. (2011). La protección del bienestar animal a través del Derecho penal. Estudios penales y criminológicos, (31), 259-304.

Higuera, J. (1998). Los malos tratos crueles a los animales en el Código Penal de 1995. Actualidad Penal, (17), 343-362.

Ley 1774 de 2016. Por medio de la cual se modifican el Código Civil, la Ley 84 de 1989, el Código penal, el Código de procedimiento penal y se dictan otras disposiciones. Diario Oficial No. 49747. Congreso de la República de Colombia, enero de 2016.

Manzanares, J. (2015). La reforma del Código Penal de 2015. Madrid: La ley.

Martínez-Buján, C. (2004). Derecho Penal. Parte Especial. En J. L. González (Coord.), Derecho Penal. Parte Especial (pp. 544-594 y 644-766). Valencia: Tirant lo Blanch.

Martínez-Buján, C. (2015). Derecho. Penal Parte Especial. En J. L. González (Dir.), Derecho Penal. Parte Especial. (4 ed). Valencia: Tirant lo Blanch.

Mosterín, J. y Riechmann, J. (1995). Animales y ciudadanos. Madrid: Talasa.

Muñoz, F. (2007). Derecho Penal. Parte Especial (16 a ed). Valencia: Tirant lo Blanch.

Muñoz, F. (2015). Derecho Penal. Parte Especial (20ª ed.). Valencia: Tirant lo Blanch.

Muñoz, J. (2007). Los delitos relativos a la flora, fauna y animales domésticos. O de cómo no legislar en Derecho Penal y cómo no incurrir en despropósitos jurídicos. Revista de Derecho Penal y Criminología, (19), 309-363.

Muñoz, S. (1999). Los animales y el Derecho. Madrid: Civitas.

Organización de las Naciones Unidas -[ONU]. (1977). Declaración Universal de los derechos del animal. Londres. 
Prats, J. M.; Marques, M. y Quintero, G. (Dir.). (2004). Comentarios al Nuevo Código Penal ( $3^{a}$ ed). Navarra: Aranzandi.

Queralt, J. (2015). Derecho Penal Parte Especial. (1 $1^{\text {a }}$ ed.). Valencia: Tirant lo Blanch.

Reino de España. Fiscalía General del Estado (2011). Circular 7/2011 sobre criterios para la unidad de actuación especializada del Ministerio Fiscal en materia de medio ambiente y urbanismo.

Reino de España. Ley 8 de 1991. De protección de animales. BOE No. 152. Comunidad Autónoma de Canarias, junio de 1991.

Reino de España. Ley 22 de 2003. De protección de animales. BOE No. 189. Comunidad Autónoma de Cataluña, agosto de 2003.

Reino de España. Ley Orgánica 15 de 2003. Por la que se modifica la Ley Orgánica 10 de 1995, de 23 de noviembre, del Código Penal. BOE No. 283. Congreso de los Diputados, noviembre de 2003.

Reino de España. Ley 28 de 2010. De modificación del artículo 6 del texto refundido de la Ley de protección de los animales, aprobado por el Decreto legislativo 2/2008. BOE No. 205. Comunidad Autónoma de Cataluña, agosto de 2010.

Reino de España. Ley Orgánica 5 de 2010. Por la que se modifica la Ley Orgánica 10 de 1995, de 23 de noviembre, del Código Penal. BOE No. 152. Congreso de los Diputados, junio de 2010.

Reino de España. Ley 6 de 2013. De modificación de la Ley 32/2007, de 7 de noviembre, para el cuidado de los animales, en su explotación, transporte, experimentación y sacrificio. BOE No. 140. Jefatura de Estado, junio de 2013.

Reino de España. Ley Orgánica 1 de 2015. Por la que se modifica la Ley Orgánica 10 de 1995, de 23 de noviembre, del Código Penal. BOE No. 77. Congreso de los Diputados, marzo de 2015.

Real Decreto 53 de 2013 de 1 de febrero, por el que se establecen las normas básicas aplicables para la protección de los animales utilizados en experimentación y otros fines científicos, incluyendo la docencia. BOE No. 34. Ministerio de la Presidencia.

Ríos, J. (2008). Los animales como posibles sujetos de Derecho Penal. http:/ / www. unifr.ch/derechopenal/articulos.

Roca, L. (2000). Algunas reflexiones sobre los animales y el Derecho Penal. En particular el artículo 631 del Código Penal. Actualidad Penal, (18), 397-418. Salt, S. (1999). Los derechos de los animales. Madrid: Los libros de la catarata. 